\title{
Do Maternal Micronutrient Deficiencies Program the Body Composition and Behavior of the Offspring? Probable Underlying Mechanisms
}

\author{
Anand Kumar Kalle ${ }^{1,2}$ Shampa Ghosh ${ }^{1}$ Anju Elizabeth Thomas ${ }^{1}$ Raghunath Manchala ${ }^{1}$ \\ ${ }^{1}$ Division of Endocrinology and Metabolism, Indian Council of \\ Medical Research-National Institute of Nutrition, Hyderabad, India \\ 2 Invivo Research Unit, Rodenta Bioserve, Hyderabad, India

\begin{abstract}
Address for correspondence Raghunath Manchala, PhD, Division of Endocrinology and Metabolism, National Institute of Nutrition, Jamai Osmania PO, Hyderabad 500604, India
\end{abstract} \\ (e-mail: mraghunath55@yahoo.com).
}

Ann Natl Acad Med Sci (India) 2019;55:170-181

\begin{abstract}
Obesity and noncommunicable diseases (NCDs) like diabetes are epidemic in India. Developmental origins of health and disease hypothesis, based on epidemiological evidence, associates maternal undernutrition and low birth weight (LBW) of the offspring with increased obesity and diabetes in their later life. Considering widespread maternal micronutrient (MN) deficiencies, LBW, and NCDs in India, we tested the hypothesis, "maternal MN deficiency per se programs the offspring for obesity and increases risk for NCDs in their later life" in rodent models. We showed in Wistar rat offspring that maternal MN (single or combined) deficiency per se: (1) increased body fat (visceral fat) and altered lipid metabolism, (2) decreased lean body and fat free mass, and (3) altered muscle function and altered glucose tolerance/metabolism and insulin sensitivity. Rehabilitation prevented vitamin but not mineral restriction-induced changes in offspring, which showed partial mitigation. Increased oxidative/steroid

Keywords

- micronutrient restriction

- body composition

- insulin resistance

- lipid and carbohydrate metabolism

- oxidative stress

- epigenetics stress, decreased antioxidant status, and inflammatory state were the associated common mechanisms in the offspring. Our attempts to assess the role of epigenetics showed that folate and/or vitamin B12 deficiencies altered mother's body composition besides that of the offspring. Additionally, in C57BL/6 mice, B12 deficiency-induced anxiety was observed in mothers and offspring. That expressions of histone modifying enzymes in mice brain and promoter methylation of adiponectin, leptin, and 11BHSD1 genes in rat offspring were altered in $\mathrm{MN}$ (B12 and $\mathrm{Mg}$ ) deficiency suggested that altered epigenetics most likely plays a role in maternal MN deficiency-induced changes in body fat/lipid metabolism and anxiety-like behavior in mothers and offspring.
\end{abstract}

\section{Introduction}

The major paradoxical factor for undernutrition, overweight, and obesity is the poor dietary intake of healthy foods and improper food habits. According to United Nations (UN) Food and Agriculture Organization, the number of undernourished people worldwide increased from 777 million in 2015 to 815 million in 2016, and most live in developing countries, ${ }^{1}$ where the number of stunted children indeed declined by $9 \%$ between 2012 and 2017. It is also reported that $46 \%$ of the global overweight children live in Asia. ${ }^{2}$ Also, there has been a worsening of adult obesity globally.

Micronutrient (MN; vitamins and minerals) deficiency, whose symptoms are sparsely visible, is called "hidden hunger" and a large portion of global population suffer from it. $^{2}$ Inadequate consumption of macro- and micronutrients impedes fetal development and badly affects infants' and children's growth. Alternately, his/her mother's malnutrition during pregnancy and lactation, through a phenomenon called the developmental origins of health and disease 
(DOHaD), increases body fat, especially visceral adiposity (i.e., storage fat) in his/her childhood. Indeed, obesity and associated noncommunicable diseases (NCDs) constitute a leading cause of death worldwide, with increasing prevalence among children and adults.

Maternal undernutrition, the greatest risk factor for low birth weight (LBW) offspring, is proposed to result in the development of NCDs in their middle age. More alarming than type-2 diabetes mellitus, is the prevalence among Indians of other NCDs: hypertension ( $30 \%$ of adults), heart attacks and most cardio vascular diseases (CVDs: 7-14\%), polycystic ovary syndrome (PCOS: $2.2-26 \%$ of adolescent girls and reproductive age group women), osteoarthritis (22-39\%), osteoporosis at age $\geq 50$ years ( $7-50 \%$ ), and chronic kidney disease (stage $\geq 3: 4-6 \%$ ). This not only indicates the intensity of the problem but also stresses the need for immediate corrective action. Indeed, according to National Family Health Survey-4 (NFHS4) data, NCDs are estimated to account for $53 \%$ of all deaths in India, ${ }^{3}$ and they are among the most serious public health problems of the 21st century.

In India, more than 165 million are obese and prevalence of obesity is higher among women than men. NFHS4 reported that in India, prevalence of obesity is more in high socioeconomic states like Andhra Pradesh, Punjab, Delhi, Telangana, and north eastern states compared with Bihar, Madhya Pradesh, Chhattisgarh, and Jharkhand, the low socioeconomic states. ${ }^{4}$ India was the global diabetes capital about a decade ago ${ }^{5}$ and with approximately $18 \%$ of Indian adults being type- 2 diabetes mellitus (T2DM) at present, ${ }^{6}$ we are soon expected to regain this dubious distinction. Overweight and obese individuals have three times greater risk to develop NCDs including metabolic syndrome, which features T2DM, CVDs and high blood pressure. Obesity can also lead to cancer, gallbladder disease, gallstones, osteoarthritis, gout, breathing problems, such as sleep apnea and asthma. The higher prevalence of obesity and overweight among Indians and its continuing increase are indeed of grave concern for India.

Interestingly, rates of obesity increase rapidly where MN deficiencies are more prevalent. ${ }^{7}$ Epidemiological studies show that deficient levels of some MNs are associated with increased body fat deposition. ${ }^{8}$ From a mechanistic view point, lower blood levels of vitamins and minerals increase adipogenesis leading to adipocyte dysfunction, which impairs glucose metabolism and insulin secretion further, resulting in impaired glucose tolerance, insulin resistance (IR), and T2DM.

UNICEF reported that approximately $16 \%$ of babies are born with low birth weight $(<2.5 \mathrm{~kg})$ globally and South Asia has the highest LBW incidence. India ranks third in having the highest percentage of LBW newborns. ${ }^{9}$ According to the death statistics report between 2010 and 2013 by census office, India, $48.1 \%$ of infant mortality (before completing postnatal 29 days) is due to LBW and premature births. ${ }^{10}$ Undernutrition is widespread among Indian women (nonpregnant, nonlactating, and also pregnant and lactating mothers). Abundant epidemiological evidence reports that Indian LBW babies are of the thin fat (thrifty) phenotype, perhaps as a consequence of DOHaD, due to maternal undernutrition during critical windows of development. ${ }^{11}$ While robust international data indicates LBW children to be at the greatest risk for adiposity, IR and associated NCDs in later lives, recent Indian data have demonstrated IR among LBW children around 8 to 12 years of age. ${ }^{12}$

More overweight/obese the persons are, more likely they are insulin resistant and at increased CVD risk. However, substantial numbers of overweight/obese individuals remain insulin sensitive and not all insulin resistant persons are obese. It has been apparent for many years that overweight/ obese individuals tend to be insulin resistant and become more insulin sensitive with weight loss. Compelling evidence indicates that CVD risk factors are present to a significantly greater extent in the subset of overweight/obese individuals that is also insulin resistant. As a corollary to this, an improvement in CVD risk with weight loss has been shown to a significantly greater extent, especially in those overweight/ obese individuals who are insulin resistant at baseline. In view of these observations, it appears reasonable to suggest that IR, a multifaceted syndrome is the link between overweight/obesity and adverse clinical syndromes related to excess adiposity. ${ }^{13}$

According to recent reports, India has the second highest number (14.4 million) of obese children in the world. ${ }^{14}$ It is estimated that 5.74 to $8.82 \%$ of Indian school children are obese. Alarmingly, $21.4 \%$ boys and $18.5 \%$ girls aged between 13 and 18, are either overweight or obese in urban south India. ${ }^{15}$ Curiously, overweight and obesity rates are increasing in children and adolescents not just of high socioeconomic groups but also in low income groups, in whom underweight still remains a major concern. Indeed, overweight and obese children are likely to stay obese into adulthood and childhood obesity greatly increases the risk of developing diabetes in young adulthood and CVDs in later life. Obesity also adversely affects hormonal development of the child. For example, girls develop puberty and menarche earlier, with irregularities in menstrual cycles (e.g., polycystic ovary disease) and also develop facial hair. Boys, on the other hand, show impaired development of external genitalia and tend to have an enlargement of their "breast" region.

Given this background, continued high prevalence of LBW and thin fat Indian babies (most likely due to maternal undernutrition and the consequent programming for high body fat and IR in offspring), taken together with reports of increasing prevalence of childhood adiposity and IR among 8- to 12-year-old Indian children and the highest NCD risk of such offspring in later life, the situation is alarming indeed. Of the various in utero factors that influence diseases in adult life, maternal undernutrition is very important. By modulating the nutrients available for transfer to fetus, maternal nutrition affects fetal growth, development, and its glucose/insulin metabolism irreversibly. Further, its effects vary, if it occurs during different windows of early development. However, studies so far, have demonstrated the role of macronutrients, for example, carbohydrates, proteins, and fats ${ }^{16-18}$ but not those of MNs, in the DOHaD. 
MN are important determinants of organism's structure and metabolism. ${ }^{19}$ Their deficiencies, common among populations of developing countries, have important public health implications that need immediate attention. ${ }^{20} \mathrm{How}-$ ever, information is scanty on the role if any of widespread maternal MN deficiencies in India, in the high prevalence of obesity and NCDs among Indians. It looks reasonable that fetal programming due to rampant MN undernutrition in pregnant Indian women could underlie or be associated with high prevalence among Indians of overweight, obesity, and associated NCDs.

Several studies indicate that some vitamins and minerals influence insulin at different levels. ${ }^{21}$ Moreover, MN deficiencies have persistent effects on many fetal tissues and organs, ${ }^{22}$ although no clinical signs of deficiency are seen in the mother. ${ }^{23}$ Also, consequences of MN imbalance during fetal/perinatal development may not manifest at the time of nutritional insult but appear later during development.. ${ }^{23}$ Multiple MN deficiencies during pregnancy and/or lactation that are common in developing world are associated with LBW and increased perinatal mortality and morbidity. ${ }^{24}$

Considering the difficulties in conducting mechanistic studies in human patients, we have performed studies in appropriate experimental animal models to validate/ negate the hypothesis, "maternal MN deficiencies per se program the offspring for higher body fat/altered body composition and changes in macronutrient metabolism, which increase their risk for obesity and associated NCDs in their later lives."

This review highlights evidence from our studies in experimental animal models that maternal MN imbalances prenatal, in utero and early postnatal, modulate body composition, behavior, and macronutrient metabolism in offspring that could contribute significantly to the obesity and IR epidemic in India.

\section{Our Studies in Rat and Mice Models}

In view of shorter life span of laboratory animals and since genetic and environmental influences can be controlled in them, substantial efforts have been put on establishing animal models for developmental programming that are relevant to human situation. ${ }^{25}$ Our initial studies in the albino, Wistar/National Institute of Nutrition (WNIN) rat models showed that chronic 50\% restriction of all MNs from mothers' diet through their phases of growth, gestation, and lactation had no significant effects per se in mothers nor on the offspring's birth weight. ${ }^{26,27}$ However, offspring born to vitamin (but not mineral) restricted mothers had lower body weight at weaning but not later. Interestingly, maternal vitamin and mineral restrictions both increased the offspring's body fat percentage (specially visceral fat) and decreased the percentage of lean body mass (LBM) and fat-free mass (FFM) but did not affect the offspring's glucose tolerance or insulin sensitivity up to 6 months of their age. ${ }^{26,27}$ Despite their similar effects on the offspring's body composition, maternal vitamin but not mineral restriction-induced changes in the offspring were preventable by rehabilitating mothers from parturition but not weaning, ${ }^{26,27}$ indicating the importance of maternal MN status during pregnancy and lactation. It was therefore of interest to delineate the mineral(s) whose restriction in the mother showed effects in the offspring.

Iron and folate deficiency are widespread among Indian women. Around $20 \%$ of Indian babies are born with LBW despite the mandatory iron and folate supplementation to all pregnant Indian mothers. ${ }^{28}$ Minerals like $\mathrm{Mg}$ and $\mathrm{Zn}$ are deficient among Indian women ${ }^{29}$ and $\mathrm{Mg}, \mathrm{Zn}, \mathrm{Mn}$, and $\mathrm{Cr}$ modulate insulin, ${ }^{30}$ the sole anabolic hormone that regulates macronutrient metabolism and is vital for fetal growth. Therefore, we assessed next, the effect of maternal dietary restriction of these minerals singly as per the study protocol presented in $\boldsymbol{- F i g . 1}$. The diet was restricted in the individual mineral by not adding its salt in the mineral mixture that was mixed with the diet. We observed no significant effects in mothers (body composition, reproductive performance, and offspring's birth weight), except that maternal $\mathrm{Zn}$ restriction decreased offspring's body weight at birth and later. Nevertheless, maternal dietary restriction of all four minerals affected the offspring's body composition (increased body fat percentage, especially visceral adiposity and decreased the percentage of LBM and FFM), ${ }^{31-39}$ similar to those seen in offspring of rat dams on $50 \%$ restriction of all minerals. ${ }^{27}$

Adipogenesis that begins in utero and accelerates neonatally, is considered a prime candidate for developmental programming. Robust literature suggests that changes in body adiposity and lipid metabolism are the earliest to occur, much before tissue IR manifests. ${ }^{40,41}$ In fact, IR is hypothesized to originate in impaired adipogenesis and/or fat metabolism. ${ }^{42,43}$ In line with these reports, chronic 50\% restriction of all vitamins/minerals ${ }^{26,27}$ or restriction of $\mathrm{Mg}$, $\mathrm{Mn}, \mathrm{Cr}$, and $\mathrm{Zn}$ singly from the mothers' diet, significantly increased body fat percentage, visceral adiposity, and plasma triglycerides in offspring, albeit the earliest time point at which these changes manifest was different among different MN restrictions. ${ }^{32,35,36}$

Normally, body fat percentage increases to compensate a decrease in the mass of muscle, another insulin sensitive tissue which is most important in postprandial glucose clearance. ${ }^{44}$ In line, we observed that $50 \%$ restriction of all vitamins/minerals or restriction of individual trace elements from mothers' diet during maternity persistently decreased the percentage of LBM and FFM (representing muscle and bone) in offspring. Taken along with our observation that despite significant increase in body fat percentage and visceral adiposity, the offspring born to MN restricted rat dams had no change in their tissue-associated fat percentage (TAF\%), ${ }^{36,37}$ seems to indicate that decreased LBM and FFM percentage in them could indeed be due to decreased muscle mass per se. Interestingly further, our observations that expression of myogenic genes/transcription factors Pax3, MyoD, Myf5, and MyoG was decreased in chromium restricted (CrR) offspring $^{37}$ not only corroborate the above inference but also indicate that decreased myogenesis and muscle development could be underlying the decrease in their percentage of LBM and FFM. 


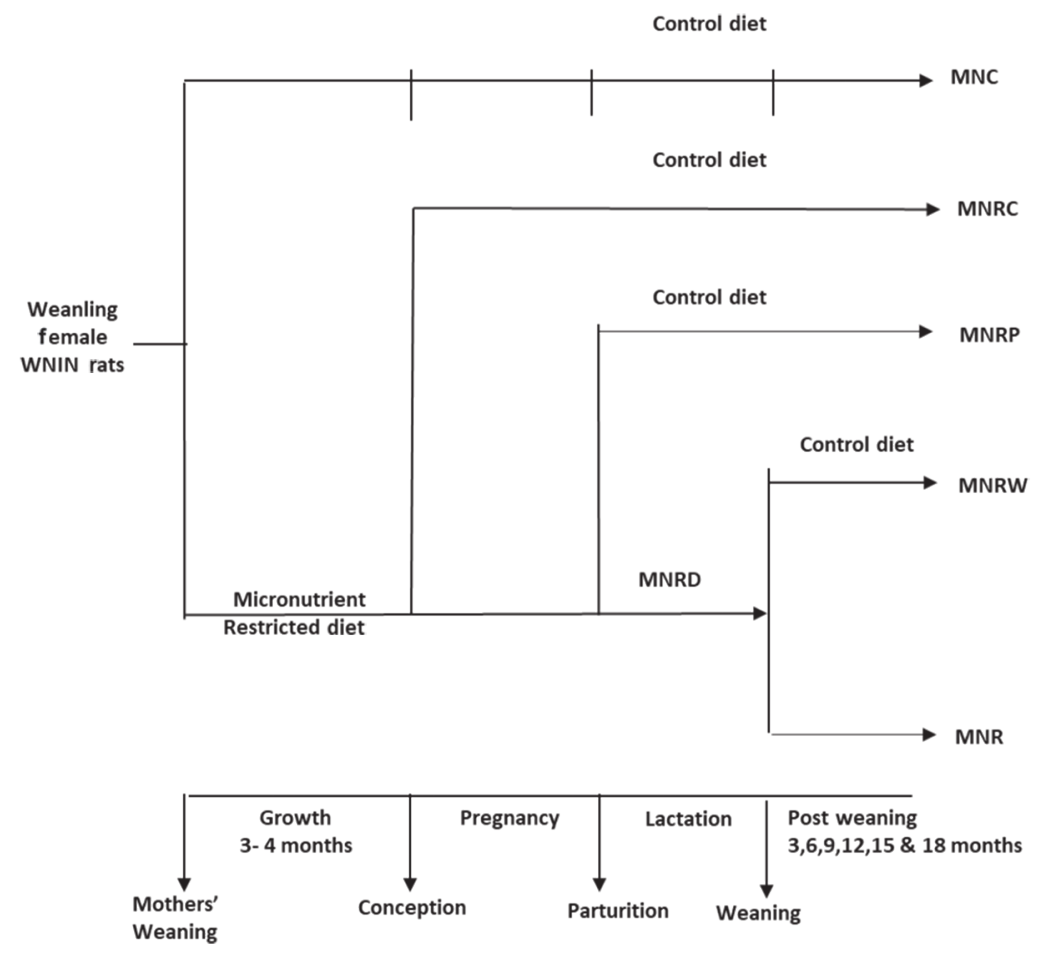

Fig. 1 Study protocol to assess the effects of maternal micronutrient restriction in Wistar rats and their offspring. MNC, micronutrient control diet; MNR, micronutrient restricted; MNRC, micronutrient rehabilitation from conception; MNRD, micronutrient restricted diet; MNRP, micronutrient rehabilitation from parturition; MNRW, micronutrient rehabilitation from weaning; WNIN, Wistar NIN.

It is known that skeletal muscle fibers are formed prenatally and the total number of fibers and/or relative proportions of different fiber types are determined mostly during fetal and early postnatal development. In line, preconceptional nutrient restriction $(\sim 50 \%)$ has been shown to decrease the total myofiber number in the fetal semitendinosus muscle. ${ }^{45}$ Also, $50 \%$ maternal undernutrition has been shown earlier to decrease total myofiber number and increase the fast myosin type-IIb isoform in the longissimus dorsi of sheep offspring, while it decreases the proportion of fast-twitch myofibers in the vastus lateralis of 14-day-old sheep. ${ }^{45,46}$ Since muscle is the major site of postprandial glucose disposal, it is reasonable that changes in muscle mass, fiber type, growth patterns, and functional characteristics of muscle fibers during perinatal period are important in programming the offspring for IR and T2D. Taken together, it is evident from our observations that maternal MN restriction during growth, pregnancy, and/ or lactation-induced changes in the offspring's body composition which suggest their predisposal to IR and associated NCDs in later life. ${ }^{39}$ Our finding that rehabilitation from as early as parturition could reverse changes only in gene expression but not the phenotype of the offspring (except in $\mathrm{Mg}$ and $\mathrm{Zn}$ restrictions) further reiterates the importance of maternal MN status in determining the offspring's body composition and their predisposal to adult onset NCDs. ${ }^{43}$

\section{Effects of Maternal MN Restriction on Adipose and Muscle Functions in Offspring}

Adipose tissue is not just a store of excess energy but is a major endocrine organ, secreting a wide range of protein factors and signals called adipokines, besides fatty acids and other lipid moieties ${ }^{47}$ Adipokines modulate adipose tissue function, lipid metabolism, and also insulin sensitivity/resistance. Therefore, we assessed next in the offspring, effects if any, of maternal MN restriction on adipose tissue function (besides those on weight and distribution), by determining changes in plasma lipid profile and levels of adipokines (associated with high body fat) in plasma and adipose tissue. We observed dyslipidemia in micronutrient restricted (MNR) offspring as evident from altered plasma lipid profile ${ }^{43}$ and in line with earlier reports, they had high plasma leptin levels which corroborated their high body fat percentage. However, hypoleptinemia seen in 50\% mineral restriction(MR) and magnesium restriction (MgR) offspring,, ${ }^{27,32}$ despite their high body fat percentage, is at variance with earlier reports showing a positive relation between them. Nevertheless, the observed hypoleptinemia is in agreement with leptin deficiency reported earlier in genetically obese rodent models and in types 1 and 2 DM patients. Thus, further studies are warranted to delineate the role if any, of hypoleptinemia in maternal MR-induced high body fat percentage in offspring. However, vitamin restriction (VR) and MR offspring had lower plasma adiponectin levels suggesting their probable IR status 
Table 1 Effects of maternal MN restriction in Wistar rat offspring

\begin{tabular}{|c|c|c|c|c|}
\hline $\begin{array}{l}\text { Maternal MN } \\
\text { restriction ( } R \text { ) }\end{array}$ & $\begin{array}{l}\text { Body } \\
\text { composition } \\
(\%)\end{array}$ & $\begin{array}{l}\text { Effects on adipose and lipid } \\
\text { metabolism }\end{array}$ & $\begin{array}{l}\text { Effects on muscle, Insulin/ } \\
\text { glucose homeostasis \& } \\
\text { Carbohydrate metabolism }\end{array}$ & Stress mechanisms \\
\hline $50 \%$ Mineral R & $\begin{array}{l}\uparrow \text { Fat, } \downarrow \text { LBM, } \\
\downarrow \text { FFM, }\end{array}$ & $\begin{array}{l}\downarrow \text { Leptin, } \downarrow \text { Adiponectin, } \\
\leftrightarrow \mathrm{TNF}-\alpha, \uparrow \mathrm{TG}, \leftrightarrow \mathrm{TC}, \leftrightarrow \mathrm{HDL}\end{array}$ & $\downarrow$ GTT Insulin secretion & $\downarrow$ GSH \\
\hline $50 \%$ Vitamin R & $\begin{array}{l}\uparrow \text { Fat, } \downarrow \text { LBM, } \\
\downarrow \text { FFM }\end{array}$ & $\begin{array}{l}\uparrow \text { Leptin, } \downarrow \text { Adiponectin, } \\
\leftrightarrow \mathrm{TNF}-\alpha, \uparrow \mathrm{TG}, \leftrightarrow \mathrm{TC}, \leftrightarrow \mathrm{HDL}\end{array}$ & $\leftrightarrow \mathrm{GTT}$ Insulin secretion & $\begin{array}{l}\uparrow \mathrm{MDA}, \downarrow \mathrm{GSH}, \uparrow \mathrm{SOD}, \\
\uparrow \mathrm{GPx}\end{array}$ \\
\hline $\mathrm{MgR}$ & $\begin{array}{l}\uparrow \text { Fat, } \downarrow \text { LBM, } \\
\downarrow \text { FFM, } \uparrow \mathrm{Al}\end{array}$ & $\begin{array}{l}\downarrow \text { Leptin, } \downarrow \text { Adiponectin, } \\
\leftrightarrow \mathrm{TNF}-\alpha, \leftrightarrow \mathrm{TC}, \leftrightarrow \mathrm{HDL}, \leftrightarrow \mathrm{T} \mathrm{T}, \\
\leftrightarrow \mathrm{FFA}, \uparrow \text { expression of FAS \& } \\
\text { FATP1 }\end{array}$ & $\begin{array}{l}\uparrow \text { Plasma insulin, } \downarrow \text { GTT Insulin } \\
\text { secretion, } \downarrow \text { Glucose uptake }\end{array}$ & $\begin{array}{l}\leftrightarrow \mathrm{MDA}, \leftrightarrow \mathrm{GSH}, \leftrightarrow \mathrm{SOD}, \\
\leftrightarrow \mathrm{GPX}, \leftrightarrow \text { catalase, } \\
\uparrow 11 \beta \mathrm{HSD} 1 \text { expression }\end{array}$ \\
\hline ZnR & $\begin{array}{l}\uparrow \text { Fat, } \downarrow \text { LBM, } \\
\downarrow \text { FFM }\end{array}$ & $\downarrow \mathrm{TG}, \downarrow \mathrm{TC}, \downarrow \mathrm{FFA}, \leftrightarrow \mathrm{FFA}$ & $\begin{array}{l}\downarrow \text { Plasma insulin, } \downarrow \text { GTT Insulin } \\
\text { secretion }\end{array}$ & \\
\hline $\mathrm{CrR}$ & $\begin{array}{l}\uparrow \text { Fat, } \downarrow \text { LBM, } \\
\downarrow \text { FFM, } \uparrow \mathrm{Al}\end{array}$ & $\begin{array}{l}\uparrow \text { plasma Leptin and } \uparrow \text { leptin } \\
\text { expression, } \leftrightarrow \text { PPAR } \Upsilon \& \text { SREBP2 } \\
\text { expression, } \downarrow \text { Adiponectin, } \\
\uparrow \text { PAI, } \uparrow \text { TNF- } \alpha, \uparrow \text { TG, } \uparrow \text { FFA, }\end{array}$ & $\begin{array}{l}\uparrow \text { Plasma glucose, } \uparrow \text { Plasma insulin, } \\
\uparrow \text { GTT Insulin secretion, } \uparrow \text { Glucose } \\
\text { uptake, } \uparrow \text { Glucose intolerance, } \\
\downarrow \text { expression of myogenesis genes } \\
\text { MyoD, Myf5, MyoG, } \downarrow \text { expression of } \\
\text { muscle atrophy genes atrogin and } \\
\text { MuRF genes }\end{array}$ & $\begin{array}{l}\uparrow \mathrm{MDA}, \downarrow \text { cata- } \\
\text { lase } \downarrow \text { SOD, } \downarrow \text { GPx, } \\
\uparrow 11 \beta \mathrm{HSD} 1 \text { expression }\end{array}$ \\
\hline $\mathrm{MnR}$ & $\begin{array}{l}\leftrightarrow \text { Fat, } \leftrightarrow \text { LBM, } \\
\leftrightarrow \text { FFM, } \uparrow \mathrm{Al}\end{array}$ & $\begin{array}{l}\leftrightarrow \text { Leptin, } \leftrightarrow \text { IL6, } \leftrightarrow \text { IL1 } \beta, \uparrow \text { TNF- } \alpha, \\
\leftrightarrow \mathrm{TG}, \leftrightarrow \mathrm{TC}, \downarrow \mathrm{HDL}\end{array}$ & $\begin{array}{l}\uparrow \text { Plasma glucose, } \downarrow \text { Plasma insulin, } \\
\downarrow \text { GTT Insulin secretion, } \uparrow \text { Glucose } \\
\text { intolerance, } \downarrow \text { Glucose uptake }\end{array}$ & \\
\hline Folate $\mathrm{R}$ & $\begin{array}{l}\uparrow \text { Fat, } \downarrow \text { LBM, } \\
\downarrow \text { FFM, } \uparrow \mathrm{Al}\end{array}$ & $\begin{array}{l}\leftrightarrow \text { Leptin, } \downarrow \text { Adiponectin, } \\
\uparrow \text { TNF- } \alpha, \leftrightarrow \mid \text { L6, } \leftrightarrow \text { IL } 1 \beta, \\
\uparrow T G \uparrow \text { Fattyacidsynthase, } \\
\uparrow \text { Acetyl-CoA-carboxylase }\end{array}$ & $\begin{array}{l}\uparrow \text { Plasma glucose, } \uparrow \text { Plasma insulin, } \\
\uparrow \text { GTT Insulin secretion, } \uparrow \text { Glucose } \\
\text { intolerance, ↔Glucose uptake, } \\
\uparrow \text { PEPCK, ↔FBPase, } \uparrow \text { G6Pase, } \\
\downarrow \text { PyK, ↔GK }\end{array}$ & $\begin{array}{l}\leftrightarrow \text { MDA, } \downarrow \text { catalase, } \\
\leftrightarrow \text { GPx, } \downarrow \text { GSH, } \uparrow \text { GSSG, } \\
\uparrow \text { Protein carbonyls, } \\
\uparrow \text { cortisol }\end{array}$ \\
\hline Vitamin B12R & $\begin{array}{l}\uparrow \text { Fat, } \downarrow \text { LBM, } \\
\downarrow \text { FFM, } \uparrow \mathrm{Al}\end{array}$ & $\begin{array}{l}\downarrow \text { Leptin, } \downarrow \text { Adiponectin, } \\
\uparrow \text { TNF- } \alpha, \uparrow \text { IL6, } \downarrow \text { IL } 1 \beta, \uparrow T G, \\
\uparrow T C, \uparrow \text { Fattyacidsynthase, } \\
\uparrow \text { Acetyl-CoA-carboxylase }\end{array}$ & $\begin{array}{l}\uparrow \text { Plasma glucose, } \uparrow \text { Plasma insulin, } \\
\uparrow \text { GTT Insulin secretion, } \uparrow \text { Glucose } \\
\text { intolerance, ↔Glucose uptake, } \\
\uparrow \text { PEPCK, } \uparrow \text { FBPase, } \leftrightarrow \text { G6Pase, } \\
\downarrow \text { PyK, ↔GK }\end{array}$ & $\begin{array}{l}\uparrow \text { MDA, } \downarrow \text { catalase, } \\
\leftrightarrow \mathrm{GPx}, \downarrow \mathrm{GSH}, \uparrow \mathrm{GSSG}, \\
\uparrow \text { Protein carbonyls, } \\
\uparrow \text { cortisol }\end{array}$ \\
\hline Folate $R+B 12 R$ & $\begin{array}{l}\uparrow \text { Fat, } \downarrow \text { LBM, } \\
\downarrow \text { FFM, } \uparrow \mathrm{Al}\end{array}$ & $\begin{array}{l}\leftrightarrow \text { Leptin, } \leftrightarrow \text { Adiponectin, } \\
\leftrightarrow \mathrm{TNF}-\alpha, \uparrow \text { IL6, } \downarrow \text { IL } 1 \beta, \leftrightarrow \mathrm{TG}, \\
\uparrow \mathrm{TC}, \uparrow \text { Fattyacidsynthase, } \\
\uparrow \text { Acetyl-CoA-carboxylase }\end{array}$ & $\begin{array}{l}\uparrow \text { Plasma glucose, } \uparrow \text { Plasma insulin, } \\
\leftrightarrow \text { GTT Insulin secretion, } \uparrow \text { Glucose } \\
\text { intolerance, } \leftrightarrow \text { Glucose uptake, } \\
\uparrow \text { PEPCK, } \leftrightarrow \text { FBPase, } \leftrightarrow \text { G6Pase, } \\
\leftrightarrow \text { PyK, } \leftrightarrow \text { GK }\end{array}$ & $\begin{array}{l}\leftrightarrow \mathrm{MDA}, \downarrow \text { catalase, } \\
\uparrow \mathrm{GPx}, \leftrightarrow \mathrm{GSH}, \uparrow \mathrm{GSSG}, \\
\leftrightarrow \text { Protein carbonyls, } \\
\uparrow \text { cortisol }\end{array}$ \\
\hline
\end{tabular}

Abbreviations: $\uparrow$, increase; $\downarrow$, decrease; $\leftrightarrow$, no change; 11BHSD1, 11-beta-hydroxysteroidehydrogenase1; Al, adiposity index; CrR, chromium restriction; FAS, fatty acid synthase; FATP1, fatty acid transport protein 1; FBPase, fructose-1, 6-bisphosphotase; FFA, free-fatty acid; FFM, fat-free mass; G6Pase, glucose-6-phosphotase; GK, glucokinase; GPx, glutathione peroxidase; GSH, reduced glutathione; GSSG, oxidized glutathione; GTT, glucose tolerance test; HDL, HDL cholesterol; IL1ß, Interleukin 1 ;; IL6, Interleukin 6; LBM, Lean body mass; MDA, malondialdehyde; MgR, magnesium restriction; MN, micronutrient; MnR, manganese restriction; PAI, plasminogen activator inhibitor; PEPCK, phosphoenolpyruvate-carboxykinase; PPAR $\Upsilon$, peroxisome proliferator activated receptor gamma; PyK, pyruvatekinase; R, restriction; SOD, superoxide-dismutase; SREBP2, sterol regulatory element binding protein 2; TC, total cholesterol; TG, triglycerides; TNF- $\alpha$, tumor necrosis factor $\alpha$; ZnR, zinc restriction.

(-Table 1). ${ }^{26,27}$ Interestingly further, changes in circulating adipokine levels were mitigated only in those offspring rehabilitated from birth but not weaning, confirming the importance of maternal vitamin and mineral nutrition during gestation and lactation in modulating these changes (- Table 2). On the other hand, maternal $\mathrm{CrR}$ modulated adipose tissue adipokine levels (adiponectin, leptin, and tumor necrosis factor [TNF]- $\alpha$ ) only in male but not female offspring, while circulating adipokine levels were influenced variably in offspring of both genders. ${ }^{34,36}$ Also, rehabilitation affected different adipokine levels variably among male and female offspring. Notwithstanding that vitamin and mineral restrictions in the mother increased body fat in offspring, it appears that probable underlying/ associated mechanism(s) leading to adiposity and functional changes could be different at least to some extent.
As for the effects of maternal MN restriction on muscle function in offspring, although fold stimulation of muscle glucose uptake by insulin was unaffected, basal glucose uptake by muscle (diaphragm) was significantly and irreversibly decreased in MgR offspring, whereas it was increased in $\mathrm{CrR}$ offspring, which could be prevented by rehabilitation albeit in male offspring. ${ }^{31,37}$ Since, both $\mathrm{MgR}$ and CrR offspring had lower percentage of LBM and FFM (muscle mass), the present results not only suggest altered basal capacity of muscle to clear glucose but also their differential sensitivity to different maternal MN restrictions, mitigation by rehabilitation, in addition to the gender differences in the effects. On the other hand, maternal Mn restriction diversely affected basal muscle glucose uptake in male and female offspring, but decreased the insulin 
Table 2 Effect of rehabilitation on chronic maternal dietary micronutrient restriction induced changes in Wistar rat offspring

\begin{tabular}{|c|c|}
\hline Maternal MN restriction ( $\mathrm{R})$ & Effect of rehabilitation on chronic maternal dietary restriction induced changes in offspring \\
\hline $50 \%$ mineral $\mathrm{R}$ & $\begin{array}{l}\text { Mineral rehabilitation from parturition or weaning had little effect on birth weight, body composition, } \\
\text { and plasma triglycerides. }\end{array}$ \\
\hline $50 \%$ vitamin $\mathrm{R}$ & $\begin{array}{l}\text { Rehabilitation from parturition or weaning prevented the changes in body fat percent, lean body mass, } \\
\text { fat-free mass, and oxidative stress. }\end{array}$ \\
\hline MgR & $\begin{array}{l}\text { Rehabilitation regimes (parturition and weaning) partially/could not corrected the changes in body } \\
\text { composition, but not the changes in glucose metabolism. While changes in FAS and FATP1 were not } \\
\text { correctible by rehabilitation, those in leptin and TNF- } \alpha \text { were corrected by rehabilitation from parturition } \\
\text { but not from weaning. } 11 \beta H S D 1 \text { expression was corrected by both rehabilitation regimes. }\end{array}$ \\
\hline ZnR & $\begin{array}{l}\text { Rehabilitation regimens (parturition and weaning) corrected the body weights of male but not female } \\
\text { offspring. Rehabilitation from parturition or weaning partly corrected the changes in the percentage of } \\
\text { body fat but had no such effect on other parameters of lipid and carbohydrate metabolisms. }\end{array}$ \\
\hline $\mathrm{CrR}$ & $\begin{array}{l}\text { Rehabilitation regimes (conception, parturition, and weaning) did not correct body adiposity but } \\
\text { restored the circulating levels of lipids and adipocytokines and, in general, corrected the changes albeit } \\
\text { partially in glucose metabolism and stress parameters, Rehabilitation partly corrected myogenic and } \\
\text { atrophic gene expression but had no effect on LBM percentage or FFM percentage or glucose uptake by } \\
\text { muscle. }\end{array}$ \\
\hline $\mathrm{MnR}$ & $\begin{array}{l}\text { Rehabilitation regimes (conception, parturition, and weaning) partially corrected the increase in TNF- } \alpha \text {. } \\
\text { Total cholesterol levels were lower in rehabilitation regimes by } 18 \text { months of age, while HDL levels were } \\
\text { improved in rehabilitation from parturition. }\end{array}$ \\
\hline Vitamin B12R & $\begin{array}{l}\text { Altered body composition, lipid profile, adipocytokine levels, increased insulin secretion, impaired } \\
\text { glucose tolerance, altered lipid and carbohydrate metabolism, etc., seen with maternal vitamin B12R } \\
\text { were reversible by B12 rehabilitation from conception but partially by rehabilitation from parturition } \\
\text { and weaning. }\end{array}$ \\
\hline
\end{tabular}

Abbreviations: B12R, B12 restriction; CrR, chromium restriction; MgR, magnesium restriction; MN, micronutrient; MnR, manganese restriction; FATP, fatty acid transport protein; FAS, fatty acid synthesis; FFM, free-fat mass; HDL, high density lipoprotein; TNF, tumor necrosis factor; ZnR, zinc restriction.

stimulated glucose uptake in both (unpublished observations). Interestingly, rehabilitation corrected the changes variably among the offspring of the two genders. It was further interesting that $\mathrm{MnR}$ offspring fed high fat diet in later life, had higher basal and insulin stimulated muscle glucose uptake than those fed normal fat diet or the manganese control diet (MNC) offspring fed high fat diet. ${ }^{48}$ It appears from these observations that maternal MN restriction affected muscle mass and function (basal and/or insulin stimulated glucose uptake), in addition to modulating their susceptibility to high fat feeding and may thus predispose offspring to develop hyperglycemia in later life ( - Tables 1 and $\mathbf{2}$ ). Overall, our results indicate that maternal MN restriction not only affected body composition (muscle and fat) of the offspring but also the function of these two important insulin sensitive tissues.

\section{Effects on Macronutrient Metabolism in the Offspring}

\section{Carbohydrate Metabolism}

Fifty percent restriction of maternal vitamins or minerals per se or their postnatal continuation did not affect fasting plasma glucose and insulin levels in offspring till 6 months of age. 26,27 Although in 6 months, old MgR offspring, fasting plasma insulin, and homeostasis model assessment of insulin resistance (HOMA-IR) index were significantly higher, ${ }^{31}$ their insulin secretion to a glucose challenge (area under curve of insulin [AUC insulin] during the oral glucose tolerance test [OGTT]) was significantly lower and irreversible ${ }^{31,32}$ by rehabilitation. In zinc restriction (ZnR) offspring, all these parameters were decreased almost irreversibly. ${ }^{33,35}$ On the other hand, maternal
$\mathrm{Cr}$ restriction raised fasting plasma glucose, insulin, HOMA IR, and also AUC of glucose and insulin during OGTT, ${ }^{38}$ albeit the effects were seen late in their life and some of them were indeed of transient nature. ${ }^{34,38}$ Interestingly, rehabilitation mitigated these changes only partly. In line with consistent fasting hyperglycemia, moderate increase was seen in phosphoenolpyruvate carboxykinase (PEPCK) expression in liver, suggesting increased gluconeogenesis (unpublished results). Maternal Mn restriction, however, induced consistent, fasting hyperglycemia along with hypoinsulinemia in the offspring. ${ }^{48}$ Interestingly, maternal Mn restriction increased the offspring's susceptibility to impaired glucose metabolism, especially when fed high fat diet in later life, as indicated by the increase in AUCs of glucose and insulin during OGTT $^{48}$ In general rehabilitation, alleviated changes due to maternal $\mathrm{Mn}$ restriction, while those due to maternal $\mathrm{Mg}$ and $\mathrm{Cr}$ restrictions were irreversible or partly reversible at the best. These findings (except in $\mathrm{CrR}$ ) are in agreement with earlier literature showing decrease in glucose-stimulated insulin secretion in the offspring of protein deficient mothers, which was proposed to be due to $\beta$-cell exhaustion or a decrease in $\beta$-cell numbers/mass similar to that in T2DM. ${ }^{49}$ It thus appears that maternal MN restriction and its postnatal continuation modulated insulin secreting capacity of the offspring under fasting and fed states, which in turn influenced glucose uptake and metabolism.

\section{Lipid Metabolism}

Hormones that affect glucose/lipid metabolism modulate the activities of enzymes and proteins involved in adipogenesis/lipid transport, for example, fatty acid synthase (FAS) and fatty acid transport proteins (FATPs) $)^{50-52}$ and obesity is 
reported to affect FAS and FATP1 expressions variably. That FAS and FATP1 expressions were higher in liver and adipose tissue of MgR offspring at 6 and 18 months of age, ${ }^{32}$ suggests that increased fatty acid synthesis and transport may underlie the increased body fat in MN restricted offspring. However, comparable levels of plasma total cholesterol, high density lipoprotein (HDL) cholesterol, free-fatty acids, and triglycerides (TGs) among control and MgR offspring at 18 months of age and no effect of rehabilitation, do not appear to corroborate the increased FAS and FATP1 expression in MgR offspring. ${ }^{32}$ Interestingly, plasma lipid profile was comparable among groups of male CrR offspring, while CrR female offspring had higher plasma TGs and free-fatty acids than controls and $\mathrm{Cr}$ rehabilitation modulated these changes. ${ }^{34}$ While changes in plasma lipid profile were inconsistent in ZnR offspring,, ${ }^{33} \mathrm{MnR}$ offspring (both genders) had high-plasma total cholesterol but varied HDL cholesterol levels. ${ }^{48}$ Interestingly, maternal Mn restriction increased circulating TGs and free-fatty acids in offspring chronically fed high-fat diet later in life compared with those fed normal fat diet or MNC offspring fed high-fat diet. ${ }^{48}$ Thus, it is evident from the results that maternal MN restriction not only affected the adipose tissue content and functions but also altered lipid metabolism.

Considered with available literature, our observations indicate that diverse nutritional insults in mothers (macroor micronutrient restrictions) cause similar phenotypic characteristics in the offspring at least with respect to their body composition and insulin secretion. While programming for obesity is undoubtedly a multifactorial process, the diversity of maternal nutrient deficiencies which increase adiposity in offspring appear to suggest some common mechanisms/ pathways underlying/associated with these effects. Apparently, any common mechanism for developmental programming of an obese/insulin resistant adult phenotype must explain how early environmental stress (maternal deficiency of diverse nutrients) can set in motion persistent biochemical and molecular changes which cause pervasive, damaging effects in their later life.

\section{Deducing the Role of Stress, Epigenetics, and 1-Carbon Metabolism}

Literature search indicates stress (oxidative/steroid), an inflammatory status, changes in taurine metabolism and epigenetics to be some common mechanisms associated with developmental programming of offspring to obesity and adult onset diseases, especially due to maternal malnutrition during pregnancy and/or lactation. ${ }^{53-57}$

Epigenetics, a mechanism proposed to underlie developmental programming involves the following: (1) methylation/demethylation of $\mathrm{CpG}$ islands in promoter regions of target genes which suppress/activate gene expression respectively; (2) methylation/deacetylation and demethylation/acetylation of histones, which activate or suppress the associated gene expression, respectively; and (3) micro-RNAs which modulate the expression of specific genes. ${ }^{55,56}$ Indeed, modulation of gene expression is dependent on interaction/balance among the above three constituent mechanisms. Interestingly, constituents 1 and 2 , which form an important portion of epigenetic mechanisms, require a methyl donor (e.g., S-adenosyl methionine [SAM]), which is supplied chiefly by the 1-carbon metabolic pathway ${ }^{58}$ and folic acid, vitamin B6 and B12 are the important MNs that regulate this pathway. Indeed, robust literature indicates that deficiency of any of these MNs modulates 1-carbon metabolic pathway (i.e., SAM availability) and, in turn, the epigenetic regulation of gene expression. ${ }^{58}$

Folate and vitamin B12 deficiencies are common in Indians, especially among women of reproductive age group, pregnant, and lactating mothers. ${ }^{59,60}$ All pregnant Indian women receive the mandatory iron and folate supplements regardless of their deficient vitamin B12 status and recent observations suggest the greater importance of the ratio of folate and vitamin B12 than their actual levels per se. ${ }^{61}$ It was hence considered essential to assess whether or not maternal deficiency of folate and/or B12 (the two MNs that regulate SAM availability directly, by modulating 1-carbon metabolic pathway) alter the body composition (body fat/ visceral adiposity) and LBM/FFM of the offspring and, if so, evaluate whether changes in epigenetic mechanisms underlie/are associated with these changes in offspring. Therefore, we evaluated in a Wistar rat model, whether or not dietary folate and/or vitamin B12 deficiency affect the body composition and reproductive performance of mothers, as also the effects of maternal folate and/or vitamin B12 deficiencies on body composition, development, and function of adipose/ muscle in the offspring. We also determined the modulation if any, of the 1-carbon pathway/production of SAM in mother/offspring, which is essential for epigenetic regulation of gene expression changes associated with offspring's body composition. . $2-66^{-6}$

Unlike the other MN deficiencies studied earlier, it was interesting that dietary folate and/or B12 restriction per se increased body weight, body fat (visceral adiposity), and altered lipid profile in female Wistar rats (mothers) before mating, albeit the differences were significant with only B12 restriction. ${ }^{62}$ Also, only the offspring born to vitamin B12-restricted dams had LBW, while those of folate and/ or vitamin B12 restricted dams weighed higher at/from weaning. ${ }^{62}$ Indeed, the offspring had higher body fat (especially visceral fat) from 3 months and were dyslipidemic at 12 months, at which time they had high levels of tumor necrosis factor $\alpha$, leptin and interleukin 6; and low levels of adiponectin and interleukin $1 \beta$ in circulation and also in adipose tissue. ${ }^{64}$ All vitamin-restricted offspring had higher activities of hepatic fatty acid synthase and acetylCoA-carboxylase and higher plasma cortisol levels. ${ }^{62}$ On the other hand, three enzymes in the $\beta$-oxidation pathway, hydroxyacyl-coenzyme A dehydrogenase, medium-chain specific acyl-CoA dehydrogenase, and 3-ketoacyl-CoA thiolase were down regulated in pups born to vitamin B12 deficient mothers (-Table 1). Interestingly an age-dependent differential expression of peroxisome proliferator activated-receptors (PPAR) $\alpha$ and $\Upsilon$ was observed 
in B12 deficient pups. ${ }^{65}$ Indeed, enriched/differential expression of 27 proteins involved in pathways that regulate amino acid, lipid, and carbohydrate metabolism was observed, and this was restored to control levels after B12 rehabilitation of restricted mothers from parturition. ${ }^{65,66}$ In conclusion, maternal and peri- or postnatal folate and/ or vitamin B12 restriction increased visceral adiposity (perhaps due to increased corticosteroid stress), altered lipid metabolism in rat offspring probably by modulating adipocyte function resulting in inflammatory status.

Although dietary vitamin B12 restriction increased the mother's body weight and fat, it decreased LBM percentage and FFM percentage but not the percentage of tissue associated fat $(\mathrm{TAF})^{62}$ indicating that the increase was only in the storage form (visceral) but not functional fat. Similarly, maternal B12R also decreased LBM percentage and FFM percentage in only male offspring, but their TAF\%, basal, and insulin stimulated muscle glucose uptake were unaffected. Nevertheless, at 12 months of age, B12R offspring had significantly higher fasting plasma glucose, insulin, HOMA-IR and also impaired glucose tolerance. ${ }^{63}$ In line, hepatic gluconeogenisis was high in them as evident from increased expression of gluconeogenic enzymes PEPCK, fructose-1, 6-bisphosphatase, and pyruvate kinase. ${ }^{63}$ Unlike maternal mineral restrictions which altered body composition in offspring of both genders, ${ }^{35,36}$ folate and/or vitamin B12 restriction altered body composition in only male but not female offspring. ${ }^{62}$ That changes in body composition, glucose, and lipid metabolism in offspring were prevented by rehabilitation from conception, ${ }^{64}$ whereas rehabilitation from parturition and weaning corrected them only partially, ${ }^{63}$ not only indicate their causal relationship but also highlight the importance of vitamin B12 during pregnancy and lactation with particular reference to growth, muscle development, glucose tolerance, and metabolism in the offspring ( - Table 2 ). Interestingly, altered body composition was intergenerationally transferred from $\mathrm{F} 1$ offspring to F2; however, the effects were seen in only male offspring but not in females suggesting the probable gender differences in the effects of maternal vitamin B12 and/or folate restriction in the offspring (unpublished data).

Maternal folate and/or vitamin B12 restrictions not only induced similar changes in body composition, carbohydrate, and lipid metabolism in the offspring as did maternal single-mineral restriction or $50 \%$ restriction of all vitamins and minerals from the mother's diet but were also associated with altered expression of relevant genes that could be mitigated by folate and/or vitamin B12 rehabilitation. ${ }^{65}$ Therefore, it appears that modulation of epigenetics and other common mechanisms could underlie/be associated with the maternal MN (folate and/or vitamin B12) restriction-induced phenotypic changes in the offspring. ${ }^{65,66}$

Mouse genome is closer to human genome and is rich in $\mathrm{CpG}$ islands ${ }^{67}$ that undergo methylation/demethylation affecting gene expression and hence mouse is considered a model better suited to assess epigenetic changes. Therefore, studies were conducted in C57BL/6 mice to decipher the underlying/associated epigenetic changes if any.
In partial agreement with our findings in Wistar rat models, we observed that severe but not moderate vitamin B12 deficiency impaired lipid profile, induced adiposity, and caused adverse gestational outcome in mothers. ${ }^{68}$ On the other hand, both severe and moderate maternal vitamin B12 deficiencies caused negligent care of their pups and anxiety in them in addition to the effects on the body composition (increased visceral adiposity), dyslipidemia, fasting hyperglycemia, and insulin resistance in the offspring, ${ }^{69}$ besides catch up growth and most of these changes commenced early in the offspring's life. However, only severe vitamin B12 deficiency-induced anhedonia/depression in mothers and was associated with the thinning of interneuronal connections in prefrontal cortex and hippocampus. ${ }^{70}$ Offspring of both severe and moderately B12 deficient dams also showed pronounced anxiety behavior whereas offspring of severely B12 deficient dams developed depression ( - Fig. 2). ${ }^{70}$ Rehabilitation from parturition but not weaning was beneficial albeit in only delaying the onset of deleterious effects in offspring whereas rehabilitation from parturition and weaning could both prevent onset of depression but not anxiety in the offspring. ${ }^{70}$

That alterations in epigenetic mechanisms may be associated with changes in body composition ${ }^{71}$ and macronutrient metabolism in offspring is evident from the methylated DNA immunoprecipitation (MeDIP) sequencing of liver in control and B12 restricted rat offspring. A total of 214 hypermethylated and 142 hypomethylated sites were observed in the $10 \mathrm{~kb}$ region upstream of transcription start site (TSS), which is enriched in genes involved in fatty acid metabolism and mitochondrial transport/metabolism. ${ }^{65}$ Interestingly, behavioral changes in severely B12 deficient female mice were associated with epigenetic changes as evident from the overexpression of both writer (histone-methyl-transferase, SUV420H1) and eraser (histone deacetylase, HDAC4) classes of histone modifying enzymes. ${ }^{70}$ Thus vitamin B12 restriction appears to alter promoter DNA methylation and/or modulate histone modifying enzyme expression, which in turn regulate the expression of genes involved in important metabolic processes influencing the offspring's phenotype. ${ }^{66,69,70}$ That B12 rehabilitation from conception reversed methylation of many of these regions to control levels probably suggests their causal relationship with the metabolic phenotypes. ${ }^{65,66}$ Whether or not similar epigenetic alterations underlie the behavioral changes seen in the offspring, remain to be deciphered.

In line with our observations that offspring born to MN restricted dams had increased stress (oxidative/glucocorticoid) and inflammation (high levels of inflammatory and/or low levels of anti-inflammatory cytokines in circulation and/or adipose tissue), we observed that chronic dietary $\mathrm{Mg}$ restriction increased inflammation ( $\uparrow$ leptin, MCP1, interleukin $1 \beta[$ IL1 $\beta$ ], PAI active, IL6, and TNF- $\alpha$ ) and glucocorticoid stress in pregnant mothers ${ }^{72,73}$ who intriguingly had high-adiponectin levels. Indeed changes in inflammatory status and steroid stress were observed even in placenta and embryo on gestational day 15 and in the offspring at 6 months of their age. ${ }^{73}$ Interestingly, 
A
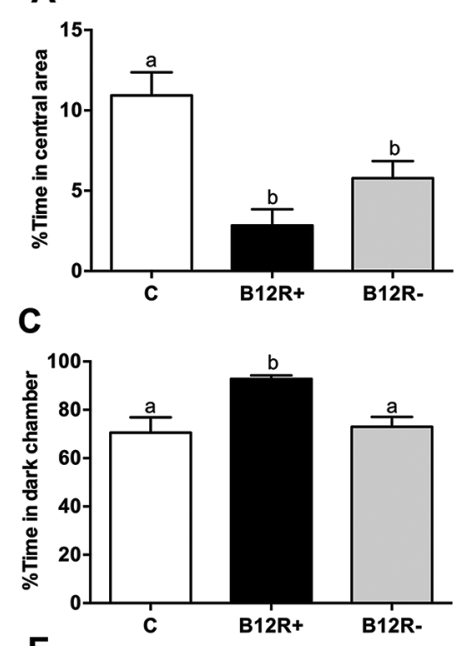

E

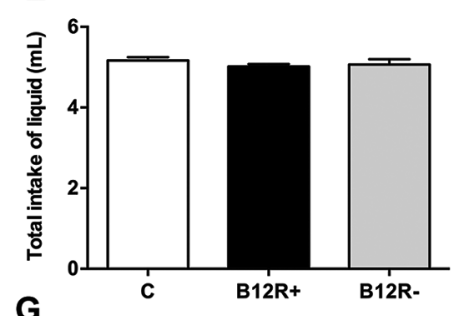

G

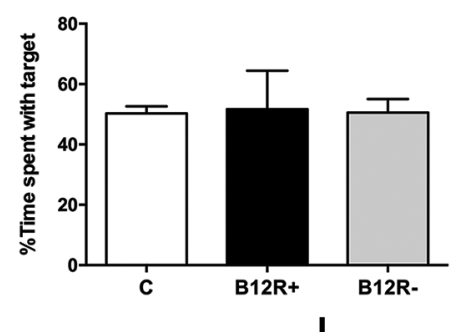

B
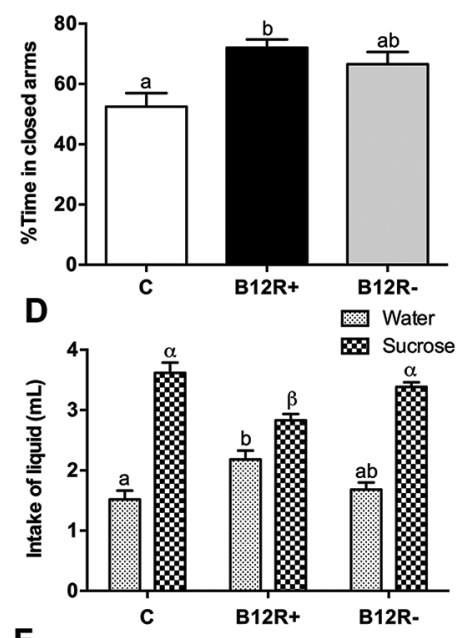

$\mathbf{F}$
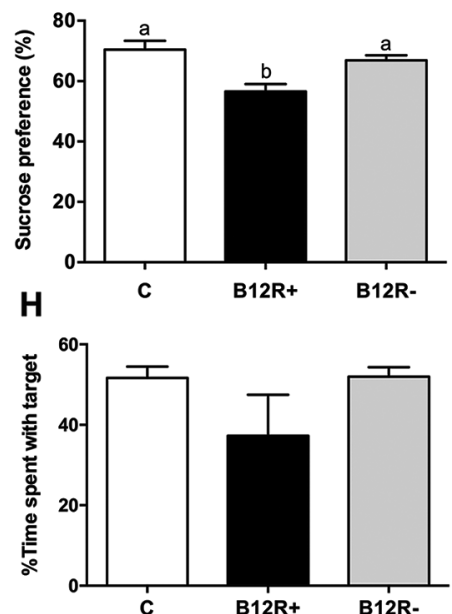

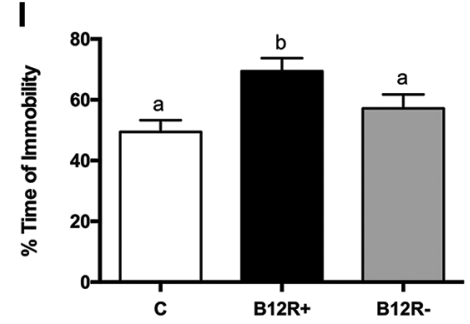

Fig. 2 Effect on behavior (evaluation of anxiety, panels A, B, C), evaluation of depression/anhedonia (panels D, E, F) and Effect on social interaction behavior (evaluation of depression panels $G, H, I)$. Values are mean \pm standard error of mean (SEM) $(n=5-7)$. Bars with different superscripts (a/b or $\alpha / \beta)$ are significantly different from one another at $p<0.05$ by one way ANOVA/Bonferroni's post hoc test. (A) Percentage time spent in central area in open field test; (B) percentage time spent in closed arms in elevated plus maze test; (C) percentage time spent in dark chamber in light-dark exploration test. (D) Differential intake of water and sucrose. (E) Total intake of liquid. (F) Sucrose preference (\%). (G) Social interaction with unfamiliar female mouse. (H) Social interaction with unfamiliar male mouse. (I) Percentage immobility time in tail suspension test. ANOVA, analysis of variance.

increased steroid stress and inflammatory status were associated with appropriate changes in the expression of $11 \beta H S D 1$ and $11 \beta H S D 2$, the enzymes which modulate the formation of the biologically active steroid ( - Fig. 3 ) and adiponectin. ${ }^{72,73}$ Altered adiponectin and 11ßHSD1 expression on GD15 appeared to be epigenetically regulated in pregnant mothers, placenta, and embryo, but not in the offspring, as indicated by the hypomethylation of $\mathrm{CpG}$ loci in the promoter region of corresponding genes (unpublished observations). Although expression of
11BHSD1, leptin, and adiponectin genes was increased in the adipose tissue of MgR offspring, it was intriguing that methylation of $\mathrm{CpG}$ loci in their gene promoters did not show corresponding change (unpublished observations). Considering that epigenetic regulation of gene expression is the effect of the net balance among different epigenetic mechanisms (methylation/demethylation of gene promoters and histones, acetylation/deacetylation of histones, and micro-RNAs), it appears premature to conclude on the role of epigenetics in these gene expression changes from 


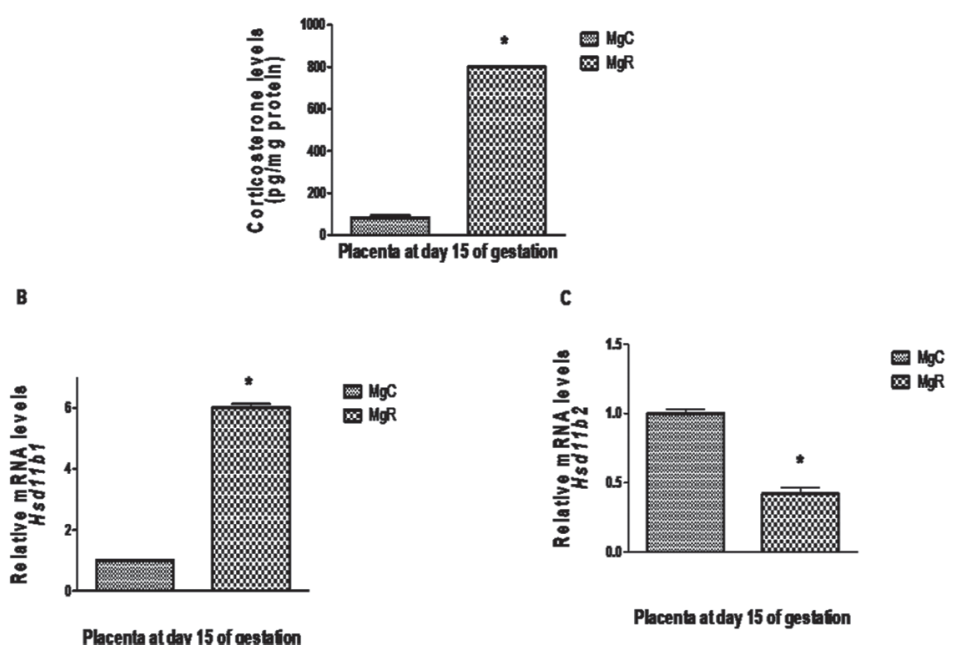

Fig. 3 Effect of chronic dietary magnesium restriction on placental (A) Corticosterone levels and expression of the genes (B) $11 \beta$ HSD1 and (C) $11 \beta$ HSD2 on gestational day 15 in WNIN female rats. Values represent mean \pm standard error of mean $(S E M)(n=6)$. MgC, control diet; MgR, magnesium restriction. Values with “*” represents significantly different by Student's $t$-test $(p<0.05)$.

our limited observations on the promoter methylation of a few genes or the expression of a few histone modifying enzymes in isolation.

Insulin resistance is often associated with increased oxidative stress and/or decreased antioxidant status. ${ }^{53,54}$ Indeed, IR and oxidative stress have been suggested to be causally related. In line with such reports suggesting a causal role for oxidative stress in IR, we observed that VR offspring, despite having markedly higher activities of antioxidant enzymes, such as superoxide-dismutase (SOD) and glutathione peroxidase (GPx) in liver, had increased oxidative stress, ${ }^{26}$ perhaps suggesting that vitamins, the nonenzymatic antioxidants act as the primary line of defense against oxidative stress in the VR offspring. Alternately, they could mean that the role of antioxidant enzymes in maintaining the VR animal's antioxidant status is limited. Increased oxidative stress and decreased activity of antioxidant enzymes were also observed in the offspring born to folate and/or vitamin B12 restricted Wistar rat dams which had high body fat/visceral adiposity, low LBM, and FFM percentage, IR, impaired glucose tolerance/metabolism, and changes in lipid profile/ metabolism later in their lives. ${ }^{62-64}$ Our findings thus appear to suggest that antioxidant enzyme activities in offspring were modulated by maternal vitamin restriction, to cope up with increased oxidative stress.

Chronic maternal mineral or Mg restriction on the other hand, had no effect on oxidative stress and/or antioxidant defense (enzymatic and nonenzymatic), ${ }^{32}$ while maternal CrR increased plasma malondialdehyde (MDA) levels and decreased hepatic SOD and Gpx activities, which curiously were mitigated variably by rehabilitation in male and female offspring. ${ }^{38}$ Increased oxidative stress was observed even in the offspring of $\mathrm{Zn}$ and $\mathrm{Mn}$ restricted rats. ${ }^{35,48}$ It appears that changes in oxidative stress/antioxidant status may be associated with maternal mineral restriction-induced changes in body fat, glucose tolerance, and impaired insulin response to glucose challenge, in addition to changes in corticosteroid stress, inflammation, and epigenetic alterations.

\section{Conclusion}

In conclusion, our studies in rodent models reported here, have demonstrated for the first time, to the best of our knowledge, that maternal MN deficiencies per se program the body composition and behavior in the offspring. Modulation of inflammation, oxidative, and/or glucocorticoid stress and epigenetics in mothers, placentae, and fetuses during gestation appears to underlie the alterations in relevant gene expression that are associated with altered body composition and behavior of the offspring. Although our findings in the rodent models are in line with the fetal programming for adult diseases hypothesis of Barker, they appear to differ from the "thin fat" phenotype suggested by Barker, in that changes in body composition and macronutrient metabolism were seen in the offspring even though they had normal birth weight.

That maternal MN restriction-induced changes in the offspring were most often, not prevented/reversed by rehabilitation from as early as conception/parturition appears to be in disagreement with the preventability/reversibility of changes by the concept "intervention during the first thousand days of the offspring's life." From our observations in the experimental animal models, it looks essential that we should ensure optimal MN status of adolescent girls, nonpregnant, and nonlactating woman and the mothers to be to enable us prevent the long-term consequences of maternal MN deficiencies in the next generation, for example, prevalence of overweight, obesity, and associated NCDs, such as T2DM, hypertension, CVDs, etc. 


\section{Conflict of Interest}

None declared.

\section{References}

1 John EM. Overview of undernutrition. Available at: https:// www.msdmanuals.com/en-in/professional/nutritional-disorders/undernutrition/overview-of-undernutrition. Accessed November 8, 2019

2 UN FAO. The state of Food security and nutrition in the world. Available at: http://www.fao.org/state-of-food-security-nutrition/en/. Accessed November 8, 2019

3 National Family Health Survey, India (NFHS-4): (2015-16). Available at: http://rchiips.org/NFHS/pdf/NFHS4/India.pdf. Accessed November 8, 2019

4 Ahirwar R, Mondal PR. Prevalence of obesity in India: A systematic review. Diabetes Metab Syndr 2019;13(1):318-321

5 Joshi SR, Parikh RM. India-diabetes capital of the world: now heading towards hypertension. J Assoc Physicians India 2007;55:323-324

6 Little M, Humphries S, Patel K, Dewey C. Decoding the type 2 diabetes epidemic in rural India. Med Anthropol 2017;36(2):96-110

7 Monteiro CA, Moura EC, Conde WL, Popkin BM. Socioeconomic status and obesity in adult populations of developing countries: a review. Bull World Health Organ 2004;82(12):940-946

8 Via M. The malnutrition of obesity: micronutrient deficiencies that promote diabetes. ISRN Endocrinol 2012;2012:103472

9 UNICEF. Low birth weight. Available at: https://data.unicef.org/ topic/nutrition/low-birthweight/. Accessed November 8, 2019

10 Office of the Registrar General \& Census Commissioner. Causes of death in India 2010-2013. Available at: http:// www.censusindia.gov.in/vital_statistics/causesofdeath.html. Accessed November 8, 2019

11 Yajnik CS, Fall CHD, Coyaji KJ, et al. Neonatal anthropometry: the thin-fat Indian baby. The Pune maternal nutrition study. Int J Obes Relat Metab Disord 2003;27(2):173-180

12 Bavdekar A, Yajnik CS, Fall CHD, et al. Insulin resistance syndrome in 8-year-old Indian children: small at birth, big at 8 years, or both? Diabetes 1999;48(12):2422-2429

13 DeFronzo RA, Ferrannini E. Insulin resistance. A multifaceted syndrome responsible for NIDDM, obesity, hypertension, dyslipidemia, and atherosclerotic cardiovascular disease. Diabetes Care 1991;14(3):173-194

14 The GBD 2015 Obesity Collaborators. Health effects of overweight and obesity in 195 countries over 25 years. N Engl J Med 2017;377:13-27

15 Ranjani H, Mehreen TS, Pradeepa R, et al. Epidemiology of childhood overweight \& obesity in India: a systematic review. Indian J Med Res 2016;143(2):160-174

16 Fowden AL, Forhead AJ. Endocrine mechanisms of intrauterine programming. Reproduction 2004;127(5):515-526

17 Glazier JD, Cetin I, Perugino G, et al. Association between the activity of the system A amino acid transporter in the microvillous plasma membrane of the human placenta and severity of fetal compromise in intrauterine growth restriction. Pediatr Res 1997;42(4):514-519

18 Haggarty P. Placental regulation of fatty acid delivery and its effect on fetal growth-a review. Placenta 2002;23(Suppl A):S28-S38

19 Villar J, Merialdi M, Gülmezoglu AM, et al. Nutritional interventions during pregnancy for the prevention or treatment of maternal morbidity and preterm delivery: an overview of randomized controlled trials. J Nutr 2003;133(5, Suppl 2):1606S-1625S
20 Díaz JR, de las Cagigas A, Rodríguez R. Micronutrient deficiencies in developing and affluent countries. Eur J Clin Nutr 2003;57(Suppl 1):S70-S72

21 Chehade JM, Sheikh-Ali M, Mooradian AD. The role of micronutrients in managing diabetes. Diabetes Spectr 2009;22(4):214-218

22 Christian P, Stewart CP. Maternal micronutrient deficiency, fetal development, and the risk of chronic disease. J Nutr 2010;140(3):437-445

23 Ashworth CJ, Antipatis C. Micronutrient programming of development throughout gestation. Reproduction 2001;122(4):527-535

24 Gernand AD, Schulze KJ, Stewart CP. West KP Jr, Christian P. Micronutrient deficiencies in pregnancy worldwide: health effects and prevention. Nat Rev Endocrinol 2016;12(5):274-289

25 Rust JH. Animal models for human diseases. Perspect Biol Med 1982;25(4):662-672

26 Venu L, Harishankar N, Prasanna Krishna T, Raghunath M. Maternal dietary vitamin restriction increases body fat content but not insulin resistance in WNIN rat offspring up to 6 months of age. Diabetologia 2004;47(9):1493-1501

27 Venu L, Harishankar N, Krishna TP, Raghunath M. Does maternal dietary mineral restriction per se predispose the offspring to insulin resistance? Eur J Endocrinol 2004;151(2):287-294

28 Malhotra N, Upadhyay RP, Bhilwar M, Choy N, Green T. The role of maternal diet and iron-folic acid supplements in influencing birth weight: evidence from India's National Family Health Survey. J Trop Pediatr 2014;60(6):454-460

29 Pathak P, Kapil U. Role of trace elements zinc, copper and magnesium during pregnancy and its outcome. Indian J Pediatr 2004;71(11):1003-1005

30 Ahmed AM, Khabour OF, Awadalla AH, Waggiallah HA. Serum trace elements in insulin-dependent and non-insulin-dependent diabetes: a comparative study. Diabetes Metab Syndr Obes 2018;11:887-892

31 Venu L, Kishore YD, Raghunath M. Maternal and perinatal magnesium restriction predisposes rat pups to insulin resistance and glucose intolerance. J Nutr 2005;135(6):1353-1358

32 Venu L, Padmavathi IJ, Kishore YD, et al. Long-term effects of maternal magnesium restriction on adiposity and insulin resistance in rat pups. Obesity (Silver Spring) 2008;16(6):1270-1276

33 Venu L, Kishore YD, Padmavathi IJ, Ganeshan M, Giridharan NV, Raghunath M. Prenatal and perinatal zinc restriction: Effects on body composition, glucose tolerance and insulin resistance in rat offspring. Diab Vasc Dis Res 2008;5:232

34 Padmavathi IJ, Kishore YD, Venu L, Ganeshan M, Krishnakanth A, Raghunath M. Effect of maternal chromium restriction on body adiposity, insulin response and glucose tolerance in male and female WNIN rats. Diab Vasc Dis Res 2007;4:252

35 Padmavathi IJ, Kishore YD, Venu L, et al. Prenatal and perinatal zinc restriction: effects on body composition, glucose tolerance and insulin response in rat offspring. Exp Physiol 2009;94(6):761-769

36 Padmavathi IJN, Rao KR, Venu L, et al. Chronic maternal dietary chromium restriction modulates visceral adiposity: probable underlying mechanisms. Diabetes 2010;59(1):98-104

37 Padmavathi IJ, Rao KR, Venu L, Ismail A, Raghunath M. Maternal dietary chromium restriction programs muscle development and function in the rat offspring. Exp Biol Med (Maywood) 2010;235(3):349-355

38 Padmavathi IJ, Rao KR, Raghunath M. Impact of maternal chromium restriction on glucose tolerance, plasma insulin and oxidative stress in WNIN rat offspring. J Mol Endocrinol 2011;47(3):261-271

39 Raghunath M, Venu L, Padmavathi I, et al. Modulation of macronutrient metabolism in the offspring by maternal 
micronutrient deficiency in experimental animals. Indian J Med Res 2009;130(5):655-665

40 Smith U. Impaired ('diabetic') insulin signaling and action occur in fat cells long before glucose intolerance-is insulin resistance initiated in the adipose tissue? Int J Obes Relat Metab Disord 2002;26(7):897-904

41 Jones AP, Friedman MI. Obesity and adipocyte abnormalities in offspring of rats undernourished during pregnancy. Science 1982;215(4539):1518-1519

42 Yajnik CS. The lifecycle effects of nutrition and body size on adult adiposity, diabetes and cardiovascular disease. Obes Rev 2002;3(3):217-224

43 Rao KR, Padmavathi IJ, Raghunath M. Maternal micronutrient restriction programs the body adiposity, adipocyte function and lipid metabolism in offspring: a review. Rev Endocr Metab Disord 2012;13(2):103-108

44 Virtanen KA, Iozzo P, Hällsten K, et al. Increased fat mass compensates for insulin resistance in abdominal obesity and type 2 diabetes: a positron-emitting tomography study. Diabetes 2005;54(9):2720-2726

45 Quigley SP, Kleemann DO, Kakar MA, et al. Myogenesis in sheep is altered by maternal feed intake during the peri-conception period. Anim Reprod Sci 2005;87(3-4):241-251

46 Fahey AJ, Brameld JM, Parr T, Buttery PJ. The effect of maternal undernutrition before muscle differentiation on the muscle fiber development of the newborn lamb. J Anim Sci 2005;83(11):2564-2571

47 Coelho M, Oliveira T, Fernandes R. Biochemistry of adipose tissue: an endocrine organ. Arch Med Sci 2013;9(2):191-200

48 Ganeshan M, Sainath PB, Padmavathi IJ, et al. Maternal manganese restriction increases susceptibility to high-fat diet-induced dyslipidemia and altered adipose function in WNIN male rat offspring. Exp Diabetes Res 2011;2011:486316

49 Heywood WE, Mian N, Milla PJ, Lindley KJ. Programming of defective rat pancreatic beta-cell function in offspring from mothers fed a low-protein diet during gestation and the suckling periods. Clin Sci (Lond) 2004;107(1):37-45

50 Smith S. The animal fatty acid synthase: one gene, one polypeptide, seven enzymes. FASEB J 1994;8(15): 1248-1259

51 Martin G, Nemoto M, Gelman L, et al. The human fatty acid transport protein-1 (SLC27A1; FATP-1) cDNA and gene: organization, chromosomal localization, and expression. Genomics 2000;66(3):296-304

52 Chirala SS, Jayakumar A, Gu ZW, Wakil SJ. Human fatty acid synthase: role of interdomain in the formation of catalytically active synthase dimer. Proc Natl Acad Sci U S A 2001;98(6):3104-3108

53 Evans JL, Goldfine ID, Maddux BA, Grodsky GM. Oxidative stress and stress-activated signaling pathways: a unifying hypothesis of type 2 diabetes. Endocr Rev 2002;23(5):599-622

54 Facchini FS, Hua NW, Reaven GM, Stoohs RA. Hyperinsulinemia: the missing link among oxidative stress and age-related diseases? Free Radic Biol Med 2000;29(12):1302-1306

55 Chavatte-Palmer P, Velazquez MA, Jammes H, Duranthon V. Review: Epigenetics, developmental programming and nutrition in herbivores. Animal 2018;12(s2):s363-s371

56 Chen M, Zhang L. Epigenetic mechanisms in developmental programming of adult disease. Drug Discov Today 2011;16(23-24):1007-1018

57 Vickers MH, Sloboda DM. Strategies for reversing the effects of metabolic disorders induced as a consequence of developmental programming. Front Physiol 2012;3:242
58 Mentch SJ, Locasale JW. One-carbon metabolism and epigenetics: understanding the specificity. Ann N Y Acad Sci 2016;1363(1):91-98

59 Pathak P, Kapil U, Yajnik CS, Kapoor SK, Dwivedi SN, Singh R. Iron, folate, and vitamin B12 stores among pregnant women in a rural area of Haryana State, India. Food Nutr Bull 2007;28(4):435-438

60 Singh S, Geddam JJ, Reddy GB, et al. Folate, vitamin B12, ferritin and haemoglobin levels among women of childbearing age from a rural district in South India. BMC Nutr 2017;3:50

61 Yajnik CS, Deshpande SS, Jackson AA, et al. Vitamin B12 and folate concentrations during pregnancy and insulin resistance in the offspring: the Pune Maternal Nutrition Study. Diabetologia 2008;51(1):29-38

62 Kumar KA, Lalitha A, Pavithra D, et al. Maternal dietary folate and/or vitamin B12 restrictions alter body composition (adiposity) and lipid metabolism in Wistar rat offspring. J Nutr Biochem 2013;24(1):25-31

63 Kumar KA, Lalitha A, Reddy U, Chandak GR, Sengupta S, Raghunath M. Chronic maternal vitamin B12 restriction induced changes in body composition \& glucose metabolism in the Wistar rat offspring are partly correctable by rehabilitation. PLoS One 2014;9(11):e112991

64 Kumar KA, Rao KR, Lalitha A, Chandak GR, Shantanu S, Raghunath M. Rehabilitation mitigates changes in body fat \%, visceral adiposity and lipid metabolism in the Wistar rat offspring induced by maternal vitamin B12 restriction. Int J Med Health Sci 2017;6(2):94-100

65 Ahmad S, Kumar KA, Basak T, et al. PPAR signaling pathway is a key modulator of liver proteome in pups born to vitamin $\mathrm{B}(12)$ deficient rats. J Proteomics 2013;91:297-308

66 Ahmad S, Basak T, Anand Kumar K, et al. Maternal micronutrient deficiency leads to alteration in the kidney proteome in rat pups. J Proteomics 2015;127(Pt A):178-184

67 Han L, Su B, Li WH, Zhao Z. CpG island density and its correlations with genomic features in mammalian genomes. Genome Biol 2008;9(5):R79

68 Ghosh S, Sinha JK, Putcha UK, Raghunath M. Severe, but not moderate vitamin B12 deficiency impairs lipid profile, induces adiposity, and leads to adverse gestational outcome in female C57BL/6 mice. Front Nutr 2016;3:1

69 Ghosh S, Sinha JK, Muralikrishna B, Putcha UK, Raghunath M. Chronic transgenerational vitamin B12 deficiency of severe and moderate magnitudes modulates adiposity-probable underlying mechanisms. Biofactors 2017;43(3):400-414

70 Ghosh S, Sinha JK, Khandelwal N, Chakravarty S, Kumar A, Raghunath $M$. Increased stress and altered expression of histone modifying enzymes in brain are associated with aberrant behaviour in vitamin B12 deficient female mice. Nutr Neurosci 2018;25:1-10

71 Kalashikam RR, Inagadapa PJ, Thomas AE, Jeyapal S, Giridharan $\mathrm{NV}$, Raghunath M. Leptin gene promoter DNA methylation in WNIN obese mutant rats. Lipids Health Dis 2014;13:25

72 Rajender Rao K, Padmavathi I, Venu L, Raghunath M. Does $11 \beta-H s d 1$ associate with the development of visceral adiposity in maternal Mg restricted Wistar/Nin Rat offspring? Endocrinol Metabol Syndrome 2012;S7:002

73 Thomas AE, Inagadapa PJN, Jeyapal S, Merugu NM, Kalashikam RR, Manchala R. Maternal magnesium restriction elevates glucocorticoid stress and inflammation in the placenta and fetus of WNIN rat dams. Biol Trace Elem Res 2018;181(2):281-287 